\title{
Karakter Antomi Daun Tumbuhan Mangrove Akibat Pencemaran di Hutan Mangrove Kabupaten Cilacap
}

\author{
Siti Samiyarsih ${ }^{1^{*}}$, Tata Brata $\mathrm{S}^{1)}$. dan Juwarno ${ }^{1)}$ \\ 1) Fakultas Biologi Universitas Jenderal Soedirman \\ *email : asih.fbio@gmail.com
}

\begin{abstract}
This research was aimed to observe the anatomical character of mangrove plants. Leave and examine the differences from leaves anatomical character of mangroves in Donan river and Tritih forestin Cilacap regency a sanself adaptation indicator. The method which his used was survey method by collecting leaves sample of each mangrove plants. The sample was preparate dusing embedding method, and stained with safranin $1 \%$. The parameter of variable which is observed in leaves anatomical character hickness of leaves, leaves mesophyll thickness, cuticle thick ness, stomata length size, and amount of stomata and trichomes per $1 \mathrm{~mm}^{2}$ leaves area. The data were analyzed witht-test for examining anatomical character difference. The results showed that four usual types of mangrove plants suchas Achantus ilicifolius, Rhizospora mucronata, Aegiceros corniculatum, and Bruguiera gymnorrhiza have similar leaves anatomical structure. The anatomi calcharacter from polluted habitat were different from unpolluted habitat. This differences was showed in leaves mesophyll thickness, cuticle thickness, stomata length size, and amount of stomata and trichomes per $1 \mathrm{~mm}^{2}$ leaves area.
\end{abstract}

Keyword : anatomical character of leave, mangroveplants, pollution, Cilacap

\section{Pendahuluan}

Ekosistem mangrove merupakan daerah pertemuan antara ekosistem laut dan ekosistem daratan yang mempunyai sifat fisika kimia yang bervariasi, sehingga memiliki karakteristik ekologi yang unik dan khas. Salah satu ekosistem mangrove yang masih dapat dijumpai dan kaya akan nutrient di Pulau Jawa adalah ekosistem hutan mangrove di Kabupaten Cilacap (Yani et al., 2004). Meskipun hutan mangrove Cilacap sudah mengalami gangguan yang cukup berat, namun secara alami vegetasi akan tumbuh dan berkembang sesuai dengan daya adaptasinya. Perubahan ini terjadi sebagai hasil proses suksesi selama kurun waktu tertentu (Khazali, 2001).

Setiap jenis tumbuhan mangrove memiliki kemampuan adaptasi yang berbeda-beda terhadap kondisi lingkungan seperti kondisi tanah, salinitas, temperatur, curah hujan dan pasang surut (Sulistiyowati, 2009). Sauren (2004) melaporkan bahwa kadar garam air dan tanah berpengaruh langsung pada arsitektur daun vegetasi mangrove.

Adaptasi vegetasi mangrove terhadap kadar garam tinggi antara lain memiliki sel-sel khusus pada daun yang berfungsi untuk menyimpan garam, berdaun tebal dan kuat yang banyak mengandung air untuk mengatur keseimbangan garam. Daun mempunyai struktur stomata yang khas untuk mengurangi penguapan (Arisandi, 2002).

Beberapa spesies tumbuhan mangrove yang mampu bertahan pada kondisi tercemar, nantinya dapat dimanfaatkan untuk pengembangan konservasi lahan mangrove, khususnya pada daerah yang letaknya dekat dengan kegiatan industri. Kemampuan organakar tumbuhan mangrove dalam menyerap bahan pencemar juga dapat memberikan tempat yang kondusif bagi ikan dan organism lainnya. Ekosistem mangrove di Segara Anakan Cilacap telah menjadi pusat perhatian pemerhati lingkungan baik nasional maupun internasional, karena Segara Anakan mempunyai ciri yang berbeda dengan zonasi hutan 
mangrove pada umumnya, yaitu berbentuk deretan vegetasi tipis membujur searah dengan garis pantai (Suparjana \& Yani, 2006)

Tujuan dari penelitian ini adalah : (1). Mempelajari struktur dan karakter anatomi daun beberapa tumbuhan mangrove di Sungai Donan dan Hutan Tritih Kabupaten Cilacap. (2). Mengetahui perbedaan karakter anatomi daun beberapa tumbuhan mangrove di Sungai Donan dan Hutan Tritih Kabupaten Cilacap sebagai indicator adaptasi terhadap pencemaran.

\section{Metode Penelitian}

Penelitian dilakukan dengan menggunakan metode survei. Materi

\section{Hasil dan Pembahasan}

Pengamatan terhadap struktur anatomi daun menunjukkan bahwa ke 4 spesies tumbuhan mangrove yang diamati, yaitu Acanthus ilicifolius, Rhizophor amucronata, Aegiceros corniculatum dan Bruguiera gymnorrhiza yang tumbuh di Sungai Donan dan Hutan Tritih Kabupaten Cilacap mempunyai struktur anatomi daun yang sama. Struktur anatomi daun tersebut terdiri dari epidermis sebagai jaringan dermal, mesofil sebagai jaringan dasar dan jaringan pengangkut. Pada lapisan dinding sel epidermis sebelah luar dilapisi oleh lapisan kutikula, dan diantara sel-sel epidermis ini terdapat derivat-derivat sel epidermis, yaitu stomata dan trikomata. Berdasarkan hasil analisis menunjukkan adanya perbedaan yang nyata pada tebal mesofil daun, tebal kutikula, ukuran panjang stomata, jumlah stomata dan jumlah trikomata per $1 \mathrm{~mm}^{2}$ luas daun. Hasil pengamatan terhadap karakter anatomi daun beberapa tumbuhan mangrove adalah sebagai berikut :

\section{Tebal daun}

Hasil analisis uji $\mathrm{t}$ menunjukkan bahwa daun beberapa tumbuhan mangrove yang hidup di Sungai Donan lebih tebal dengan tebal daun rata-rata yaitu $595,2 \mu \mathrm{m}$, sedang tebal daun rata- penelitian adalah sampel daun beberapa tumbuhan mangrove, yaitu Achantus ilicifolius, Rhizospora mucronata, Aegiceros corniculatum, dan Bruguiera gymnorrhiza yang tumbuh di Sungai Donan dan Hutan Tritih Kabupaten Cilacap. Pembuatan preparat anatomi daun dengan metode embedding, pewarnaan dengan safranin $1 \%$ dalam alcohol 70\% (Samiyarsih et al., 2014). Variabel yang diamati adalah karakter anatomi daun dengan parameter yang di ukur : tebal daun, tebal mesofil daun, tebal kutikula, panjang stomata, jumlah stomata dan trikomata per $1 \mathrm{~mm}^{2}$ luas daun. Data yang diperoleh dianalisis dengan uji t untuk mengetahui perbedaan karakter anatominya.

rata tumbuhan mangrove di Hutan Tritih adalah 559,4 $\mu \mathrm{m}$. Secara umum daun R.mucronata di Sungai Donan paling tebal dengan tebal rata-rata 689,2 $\mu \mathrm{m}$. Irisan melintang daun R. mucronata dapat dilihat pada Gambar 1. Menurut Salisbury dan Ross (1995), sukulensi atau tebal daun merupakan upaya untuk menolak kekeringan dengan cara menyimpan air dalam jaringan sukulensinya. Pada jenis tumbuhan yang hidup di daerah yang berkadar garam tinggi, maka kelebihan garam akan di encerkan dan ditimbun dalam vakuola untuk mengurangi laju kehilangan air saat terjadi peningkatan suhu. Arisandi (2002) menambahkan bahwa adaptasi yang dikembangkan R.mucronata dalam merespon dan menanggulangi konsentrasi toksik pada lingkungan tercemar seperti Sungai Donan, yaitu dengan meminimumkan pengaruh toksik yang ada di sekitarnya melalui pendekatan dilusi atau pengenceran bahan toksik yang terserap.

Tingginya kadar salinitas kedua perairan yang relatif sama mengakibatkan tingkat penyimpanan air dalam upaya mengatur kadar garam di dalam sel juga tidak memperlihatkan variasi yang begitu besar, sehingga tidak mempengaruhi ketebalan daunnya. Menurut Sauren (2004), penambahan sukulensi daun berhubungan dengan penambahan salinitas substrat. Adanya jaringan 
penyimpan air lapisan hipodermal, daun mangrove menjadi tebal dan sukulen, yang terkait dengan kapasitas penyimpan air.

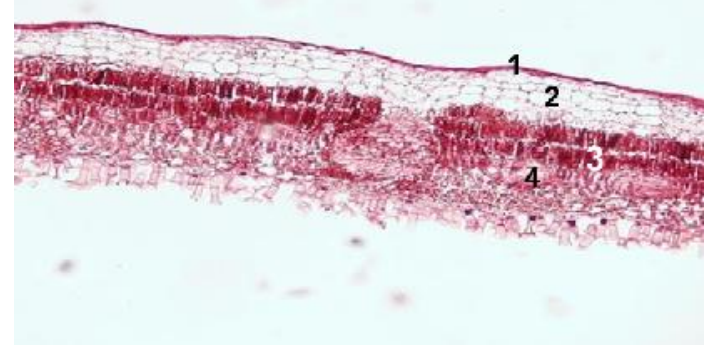

Gambar 1. Penampang melintang daun R. mucronata yang tumbuh di daerah tidak tercemar (perbesaran 100X). 1) epidermis atas ; 2) hipodermis; 3) parenkim palisade; 4) parenkim spons.

\section{Tebal kutikula}

Kutikula bersama-sama dengan epidermis berperan dalam pertahanan struktural daun. Berdasarkan analisis uji t, tebal kutikula daun beberapa tumbuhan mangrove di Sungai Donan berbeda dengan di Hutan Tritih. Secara umum daun tumbuhan mangrove di Sungai Donan mempunyai kutikula lebih tebal, dengan tebal kutikula rata-rata adalah 4,96 $\mu \mathrm{m}$. Sedangkan daun tumbuhan mangrove di Hutan Tritih mempunyai tebal kutikula rata-rata $3,22 \mu \mathrm{m}$. Adanya perbedaan yang sangat nyata pada ketebalan kutikula daun beberapa tumbuhan mangrove yang tumbuh di habitat berbeda ini, menunjukkan adanya penyesuaian diri terhadap pencemaran yang terjadi pada habitatnya. Di antara 4 jenis tumbuhan yang diamati, kutikula paling tebal terdapat pada B. gymnorrhiza dengan tebal kutikula berkisar antara 7 $13 \mu \mathrm{m}$, sedangkan pada daun A. corniculatum mempunyai kutikula paling tipis, berkisar antara 0,38-0,8 $\mu \mathrm{m}$.

Hidayat (1995) mengatakan bahwa tebal kutikula pada setiap tumbuhan beragam serta perkembangannya dipengaruhi oleh keadaan lingkungan. Hutahaean et al. (1999) menyatakan mekanisme perubahan struktural terhadap lingkungan berhubungan dengan karakter anatomi yang meliputi adanya lapisan lilin, ketebalan kutikula, kerapatan dan ukuran stomata, inti sel serta trikomata. Kutikula mempunyai fungsi sebagai jaringan pelindung bagi sel-sel daun. Fungsi ini meliputi perlindungan tehadap penetrasi cahaya matahari dan masuknya $\mathrm{CO}_{2}$ ke dalam sel-sel daun (Heddy,1990).

\section{Tebal mesofil daun}

Berdasarkan analisis uji $\mathrm{t}$, secara umum tebal mesofil daun beberapa tumbuhan mangrove di Sungai Donan lebih tebal dibandingkan daun tumbuhan mangrove yang hidup di Hutan Tritih. Daun tumbuhan mangrove di Sungai Donan mempunyai tebal mesofil rata-rata 479,15 $\mu \mathrm{m}$, sedangkan daun tumbuhan mangrove di Hutan Tritih mempunyai tebal mesofil rata-rata $374,0 \mu \mathrm{m}$.

Daun yang hidup di daerah tercemar maupun daerah tidak tercemar memiliki parenkim palisade yang terdiri dari 2-3 lapisan sel dan tersusun rapat satu sama lain (Gambar 2). Perbedaan jaringan mesofil daun yang tumbuh di habitat berbeda tersebut adalah pada luas ruang antar sel di antara parenkim spons. Ruang antar sel pada daun yang tumbuh di daerah tercemar lebih kecil dibandingkan dengan ruang antar sel pada daun yang hidup di daerah tidak tercemar. Menurut Fahn (1991) dan Hidayat (1995), ruang antar sel ini berhubungan dengan efisiensi fotosintesis. Sistem ruang antar sel memudahkan pertukaran gas yang cepat. Karbondioksida yang digunakan pada fotosintasis diperoleh dari atmosfir yang biasanya sekitar $0,03 \%$ dari volume udara. Lapisan kutikula relative kedap gas, senyawa karbondioksida memasuki daun melalui stomata. Selanjutnya gas ini berdifusi ke dalam sistem ruang antar sel dan larut dalam air yang menjenuhkan dinding sel-sel mesofil. Fotosintesis yang berlangsung efisien menghasilkan pertumbuhan yang optimal bagi suatu tumbuhan. Hal ini terlihat dari pertumbuhan tumbuhan mangrove yang lebih baik di habitat tidak tercemar 
dibandingkan tumbuhan di habitat tercemar.

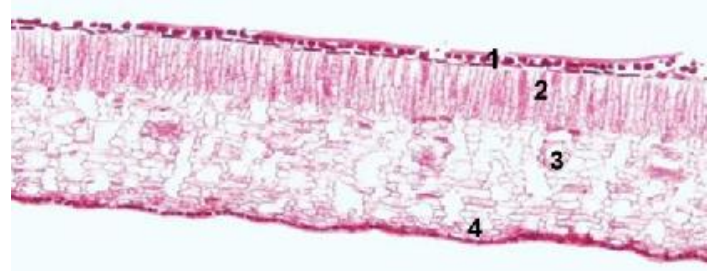

Gambar 2. Penampang melintang daun B. gymnorrhiza yang tumbuh di daerah tidak tercemar (perbesaran100X). 1) epidermis atas; 2) parenkim palisade; 3) parenkim spons ; 4) epidermis bawah.

\section{J umlahstomata}

Diantara sel epidermis daun terdapat stomata, berupa porus yang dibatasi oleh 2 sel penutup. Pengamatan pada daun beberapa tumbuhan mangrove yang hidup pada daerah tercemar menunjukkan jumlah stomata yang relative lebih sedikit yaitu rata-rata $147 / \mathrm{mm}^{2}$ bila dibandingkan jumlah stomata daun di perairan tidak tercemar rata-rata sebesar 402/mm² (Gambar 3).
Lebih sedikitnya jumlah stomata pada daun tumbuhan mangrove yang hidup di daerah Sungai Donan berhubungan dengan proses transpirasi daun pada keadaan tercekam (rawan air). Menurut Dickison (2000), menurunnya jumlah stomata per satuan luas daun merupakan respon terhadap masuknya senyawasenyawa kimia melalui stomata daun.

Sungai Donan maupun Hutan Tritih merupakan daerah payau yang mengandung kadar garam tinggi. Tingginya salinitas dan masuknya logam berat dari berbagai buangan industri di sekitar perairan serta terakumulasi di dalam perakaran mangrove, akan berakibat pada tingginya konsentrasi ion terlarut tubuh tumbuhan. Akar dengan potensial air rendah dari pada larutan tanah di sekitarnya akan mengalirkan air ke badan perairan, akibatnya potensial osmotik daun menjadi negatif atau lebih kecil dari nol. Keadaan ini akan mengakibatkan proses fisiologis tumbuhan mangrove menjadi terganggu. Untuk mengantisipasi keadaan ini tumbuhan mangrove cenderung mempunyai transpirasi yang rendah pada siang hari, sebagai upaya untuk mengurangi penguapan air yang berlebih baik melalui stomata, lenti sel maupun kutikula.
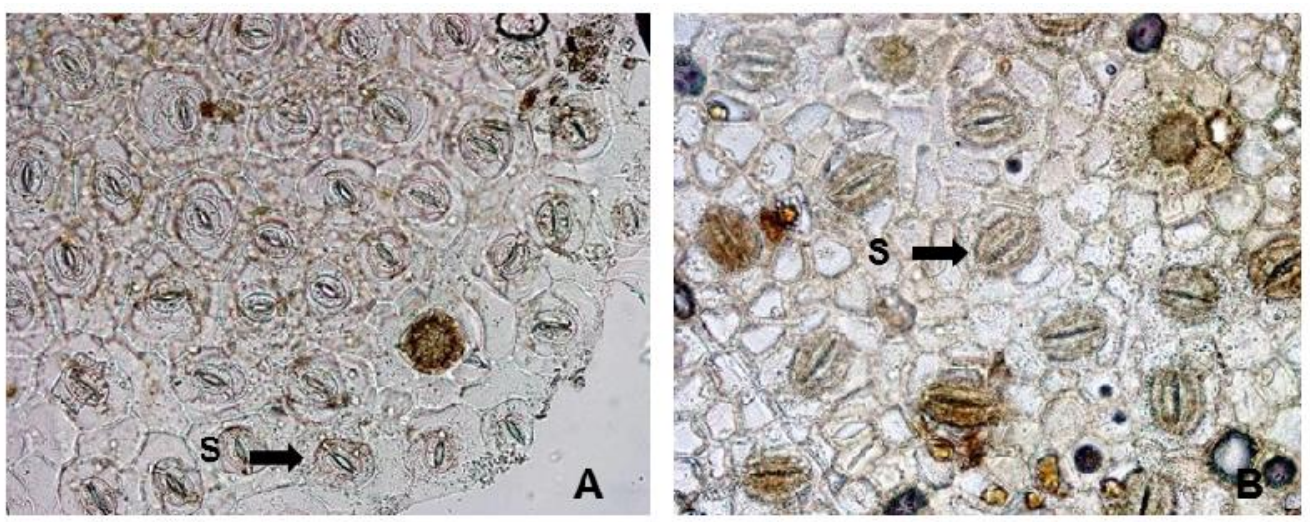

Gambar 3. Stomata daun R. mucronata yang tumbuh di habitat tidak tercemar (A) dan habitat tercemar (B), (perbesaran 400X). $S=$ stoma.

\section{Panjang stomata}

Hasil analisis uji t terhadap panjang stomata pada daun tumbuhan mangrove di kedua habitat menunjukkan berbeda sangat nyata. Stomata daun pada habitat tercemar secara umum lebih panjang dibandingkan dengan stomata daun pada habitat tidak tercemar. Panjang stomata daun di habitat tercemar berkisar antara 
13,6 - 24,8 $\mu \mathrm{m}$, sedangkan panjang stomata daun di habitat tidak tercemar berkisar antara $10-23,8 \mu \mathrm{m}$. Stomata dalam keadaan membuka akan memudahkan uap air menghilang melalui transpirasi stomata. Membukanya stomata karena mengembangnya dinding-dinding sel- sel penutup ini akan menambah panjang keliling sel-sel penutup stomata. Hal ini mengakibatkan sel-sel penutup dalam keadaan stomata tertutup semakin panjang. Saat stomata membuka itulah terjadi difusi molekul $\mathrm{CO}_{2}$ dan $\mathrm{O}_{2}$ dari dan keluar jaringan serta melepaskan molekul $\mathrm{H}_{2} \mathrm{O}$ dari daun.

\section{J umlah trikomata}

Daun halofit seringkali memperlihatkan ciri-ciri tumbuhan xerofit, antara lain permukaan daun tertutup oleh trikomata (Fahn,1991). Menurut Dickison (2000), tumbuhan yang mempunyai trikomata disebut pubescent. Daun

\section{Kesimpulan}

1. Ke-4 jenis tumbuhan mangrove yang hidup di Sungai Donan dan Hutan Tritih Kabupaten Cilacap yaitu Acanthu silicifolius, Rhizophora mucronata, Aegiceros corniculatum dan Bruguiera gymnorrhiza mempunyai struktur anatomi dan karakter anatomi daun yang sama.

\section{Daftar Pustaka}

Arisandi,P.2002.Hutan Bakau Hilang Minamata Datang. Ecological Observation and Wetland Conservation. http://www.ecoton.or.id/tulisanlengk ap.php?id=1305/16 Januari 2002.

--------, P. 2002. Mangrove Hilang, Pencemaran Pantaipun Datang. Ecological Observation and Wetland Conservation. http://www.ecoton.or.id/tulisan lengkap.php?id=1339/ 20 Juni 2002.

Departement of Forestry. 1997. National for Mangrove in Indonesia. Third pubescent dapat membiaskan cahaya matahari dan menurunkan laju transpirasi. Jumlah trikomata daun di habitat tercemar berkisar antara 93,2 - 300,8 $/ \mathrm{mm}^{2}$ luas daun, sedangkan jumlah trikomata di habitat tidak tercemar berkisar antara 88$163,2 / \mathrm{mm}^{2}$ luas daun. Secara umum jumlah trikomata daun di habitat tercemar lebih banyak dari pada jumlah trikomata daun di habitat tidak tercemar.

Tumbuhan mangrove pada umumnya mempunyai kelenjar khusus pada permukaan daunnya untuk memindahkan kelebihan garam dari lapisan mesofil dan kemudian mensekresikan ke permukaan daun (Dickison, 2000). Arisandi(2002) mengatakan bahwa Rhizophora dapat bersifat salt-excluder maupun saltaccumulator, yaitu garam terlarut tidak disekresikan ke luar jaringan tetapi ditimbum dalam jaringan (kelenjar garam) baik pada akar, batang maupun daun.

2. Daun tumbuhan mangrove di habitat tercemar memiliki ketebalan kutikula, daun dan mesofil lebih tebal, ukuran stomata lebih panjang, jumlah stomata dan trikomata lebih banyak per $1 \mathrm{~mm}^{2}$ luas daun dibandingkan dengan daun tumbuhan mangrove di habitat tidak tercemar.

Draft. Departement of Forestry, Jakarta.

Dickison, W.C. 2000. Integrative Plant Anatomy. Academic Presss, USA.

Fahn, A. 1991. Anatomi Tumbuhan. Edisi Ketiga. Gadjah Mada Univesity Press. Yogyakarta.

Heddy, S. 1990. Biologi Pertanian. Rajawali Press. Jakarta.

Hidayat, E.B. 1995. Anatomi Tumbuhan Berbiji. ITB. Bandung.

Hutahaean, E.E., Kusmana, C. \& Dewi, H.R. 1999. Study on Growth Capability of Mangrove Forest Seedling of Rhizophora mucronata, 
Bruguiera gimnorrhiza and Avicennia marina Species on Various levels of Salinity. J urnal Manajemen Hutan Tropika. 5 (1) : 77-85.

Khazali, M. 2001. Potensi, Peran dan Pengelolaan Mangrove. Seminar dan Lokakarya Nasional Nusakambangan. UGM, Yogyakarta.

Salisbury, F.B. \& Ross, C.W. 1995. Fisiologi Tumbuhan. Diterjemahkan oleh Diah $R$ Lukman dan I. Sumaryono. ITB Press, Bandung.

Samiyarsih, S., Suparjana, T.B., Juwarno, \& Sumarsono. 2014. Karakter Anatomi Daun 8 Kultivar Ubi Jalar Sebagai Respon Terhadap Penyakit Kudis. Prosiding Seminar Nasional. Percepatan Desa Berdikari melalui Pemberdayaan Masyarakat dan Inovasi Teknologi. LPPM Unsoed 20-21 November 2014
Sauren, D., 2004. Kandungan Merkuri dan Kadmium Sepanjang Kali Donan Kawasan Industri Cilacap.http://unmulac.id/dat/pub/fro ntir/Henny.pdf. 5 September 2014.

Sulistiyowati, H. 2009. Biodiversitas Mangrove di Cagar Alam Pulau Sempu. J urnal Saintek, 8(1) : 59-64.

Suparjana,T.B. \& Yani,E. 2006. Keragaman Vegetasi Mangrove dan Kualitas Air Payau Kawasan Hutan Donan di Kabupaten Cilacap. Laporan Penelitian. Fakultas Biologi Unsoed. Purwokerto.

Supriati, R. 1996. Pengaruh Salinitas Terhadap Anatomi Akar dan Daun Tumbuhan Barley (Hordeum jubatumL.). Jurnal Sains dan Teknologi 2(2) : 66 - 77 .

Yani E., Widyastuti A. \& Lestari W. 2004. Zonasi Vegetasi Mangrove di Kawasan Segara Anakan Cilacap. Biosfera21 (2): 4- 49. 